\title{
Differential impact of chronotype on weekday and weekend sleep timing and duration
}

This article was published in the following Dove Press journal:

Nature and Science of Sleep

10 September 2010

Number of times this article has been viewed

\author{
Stephanie E Roepke' \\ Jeanne F Duffy ${ }^{1,2}$ \\ 'Division of Sleep Medicine, \\ Department of Medicine, Brigham and \\ Women's Hospital, Boston, MA, USA; \\ ${ }^{2}$ Division of Sleep Medicine, Harvard \\ Medical School, Boston, MA, USA
}

Correspondence: Jeanne F Duffy

22I Longwood Avenue, BLI438,

Boston, MA 021।5, USA

Tel +l 6177327995

Fax +I 6177324015

Email jduffy@hms.harvard.edu

\begin{abstract}
Most recommendations are that adults should obtain 7-8 hours of sleep per night, although there are individual differences in self-reported sleep need. Chronotype (preference for early or late sleep timing), in combination with social demands, may affect the ability to obtain adequate sleep. This questionnaire study assessed perceived sleep need and self-reported sleep timing and duration during the week and on the weekend with respect to chronotype in visitors to the Museum of Science in Boston. Increasing age was associated with greater morningness. After adjusting for age, we found no significant association between chronotype and selfreported sleep need, or between chronotype and weekday sleep duration. However, we did find that greater eveningness was associated with a larger gap between self-reported sleep need and weekday sleep duration. On weekends, greater eveningness was associated with a longer sleep duration and greater extension of sleep, with the sleep extension achieved by later wake times. Together, these findings suggest that evening types accumulate a sleep debt during the week, despite reporting a similar sleep need and duration as morning types, and evening types then attempt to make up for that lost weekday sleep on the weekends. Studies of sleep need and sleep duration should take chronotype into account, and studies of chronotype may be confounded by the association between age and morningness, and must account for this potential confound in selection criteria and/or analysis.
\end{abstract}

Keywords: morningness-eveningness, diurnal type, circadian

\section{Introduction}

There are widespread recommendations that adults should sleep between seven and eight hours per night. ${ }^{1,2}$ Previous studies have reported that sleep durations less than six hours or exceeding nine hours are associated with increased morbidity and mortality, ${ }^{3,4}$ and studies of chronic sleep restriction indicate that such reductions can have negative metabolic, immune, and cardiovascular consequences.$^{5-7}$ However, most individuals base their sleep duration not on such long-term medical consequences of inadequate sleep, but instead on social demands combined with the more immediate alertness and performance consequences of insufficient sleep. Even so, individual sleep need is not easy to determine. Studies in which healthy individuals undergo acute or chronic experimental sleep loss demonstrate that most people are poor judges of how sleepy they really are, ${ }^{8}$ and therefore may not accurately estimate their sleep need. Controlled laboratory studies where performance is tested across the day following varying amounts of time in bed have shown that even eight hours of time in bed per night can result in performance decrements in healthy young subjects. ${ }^{2,9}$ Several carefully controlled sleep extension studies in healthy young adults have found that after many 
extended nights paying off "sleep debt", most young adults stabilize at about 8.5 hours of sleep per night, ${ }^{10-12}$ which requires nearly nine hours of time in bed to achieve. However, most adults report obtaining less than seven hours of sleep on most nights, ${ }^{13}$ and this is associated with reports of daytime fatigue, ${ }^{13}$ suggesting that those same individuals recognize that their sleep duration may be inadequate. Previous studies have found that many individuals report shorter sleep durations during the week and longer sleep durations on the weekend. ${ }^{14-16}$ This may be due to restrictions on sleep timing imposed by weekday work and social schedules, and the greater flexibility of weekend schedules.

Chronotype (the preference for early or late sleep timing) may influence both sleep need and the ability to modify sleep times between weekdays and weekends. One frequently used chronotype questionnaire is the Morningness-Eveningness Questionnaire (MEQ), ${ }^{17}$ which rates the individual on their response to a series of 19 questions about their preferred timing of different activities. Based on their total score, the individual can then be placed into one of five chronotype categories (definitely or moderately morning type, neither type, definitely or moderately evening type). ${ }^{17,18}$ In addition to differences in sleep timing between chronotypes, prior studies have found that evening types spend less time in bed and have shorter weekday sleep than morning types, while extending their sleep on the weekends. ${ }^{19}$ Evening types are also reported to have greater difficulty adjusting to weekday work or school schedules that require early start times than morning types, ${ }^{20}$ and eveningness has been reported to be associated with greater likelihood of having insufficient sleep. ${ }^{21}$ Evening types have been reported to have a more variable sleep schedule from day to day, and have been reported to tolerate night shift work better than morning types, ${ }^{22-24}$ perhaps due to their greater ability than morning types to sleep at different times of day. ${ }^{15,19}$

Using the MEQ to assess chronotype, prior studies have found that both chronobiologic factors ${ }^{18}$ and sleep homeostatic factors $^{25}$ may contribute to morningness-eveningness. One challenge of investigating chronotype and sleep is that older individuals are more likely to report that they are morning types, ${ }^{26,27}$ but the chronobiologic features of older morning types are very unlike those of young morning types, ${ }^{28,29}$ and sleep quality itself is profoundly affected by age. ${ }^{30}$ Thus, any consideration of the relationship between chronotype and sleep need must account for potential differences in age between groups of morning and evening types.

The aim of this study was to assess perceived sleep need, sleep timing and duration, and the changes in sleep timing and duration between weekdays and weekends in a sample of adults, and to relate sleep timing and duration characteristics to chronotype.

\section{Methods \\ Setting}

The study was conducted by Division of Sleep Medicine personnel at the Museum of Science, Boston, on one afternoon per week between February and May, 2009. The study was part of a research outreach program conducted by the Living Laboratory at the Museum of Science, designed to engage museum visitors in the scientific process.

Prior to beginning the study, the procedures and questionnaire were reviewed and approved by the Human Research Committee at Partners Health Care and by the Museum of Science Boston Institutional Review Board. All Division of Sleep Medicine study personnel had completed training and certification in the Collaborative Institutional Training Initiative Human Subjects Research ethics course and The Health Insurance Portability and Accountability Act as part of their employment at Brigham and Women's Hospital-Partners Health Care. They also took part in training at the Museum of Science in policies and procedures for conducting research at the Museum.

\section{Subjects}

Adults visiting the Human Body Exhibit at the Museum of Science were approached to participate in a questionnaire study. Participation was voluntary and participants did not receive monetary compensation for their involvement. A total of 171 participants began the questionnaire. Seven questionnaires were filled out by visitors whose completed responses indicated they were under the age of 18 years. These seven questionnaires were shredded and not included in any analysis. Of the remaining questionnaires, 145 were completed and returned by the participants and used for subsequent analysis.

\section{Study questionnaire and scoring}

The questionnaire contained 48 questions and took participants approximately 15 minutes to complete. It included the Horne-Östberg MEQ, ${ }^{17}$ the Pittsburgh Sleep Quality Index (PSQI), ${ }^{31}$ the Epworth Sleepiness Scale (ESS), ${ }^{32}$ the Munich Chronotype Questionnaire, ${ }^{33}$ as well as 12 additional questions addressing general sleep habits. The sleep habits portion of the questionnaire included questions about the participants' bed and wake times on weekdays and weekends, and a question about how much sleep they need "to feel refreshed and at [their] best". 
Standard scoring was used on the MEQ, and those scores were used to categorize subjects into morning or evening chronotypes. ${ }^{17}$ Participants with scores in the "definite" and "moderate" range for each chronotype were included together for further analysis. Standard scoring was also used to evaluate responses on the PSQI ${ }^{31}$ and ESS. ${ }^{32}$

Responses to the sleep habits questions were given in clock time, and these times were used to calculate sleep duration on weekdays and weekends. The calculated sleep durations were in turn used to determine the difference between reported sleep need and sleep duration, for both the weekdays and weekends. The difference in timing of both bed time and wake time between weekdays and weekends was calculated from the self-reported bed and wake times.

\section{Data analysis}

We used a mixed-model analysis to examine whether MEQ score had a significant effect on the other measures (weekday and weekend sleep timing and duration, change in bed and wake time between weekdays and weekends, sleep need, difference between sleep need and sleep duration, ESS score, PSQI score). Because of the broad age range of our sample and the reported association of greater morningness with aging, ${ }^{26,27}$ we first tested whether age and MEQ score were significantly related. After finding such an association in our dataset $\left(\mathrm{F}_{1,143}=13.00, P<0.001\right)$, we included age along with MEQ score in our model for all our subsequent analyses.

In addition to examining the entire sample using MEQ score as a continuous variable, we conducted additional analyses on the subset of participants who scored as morning or evening types on the MEQ, with their MEQ type (morning or evening) as a categoric variable. In these analyses, we also controlled for age by including it in our statistical model. Statistical analyses were performed using SAS software (SAS Institute Inc., Cary, NC).

\section{Results}

\section{Entire sample}

The 145 completed questionnaires were from adults whose ages ranged from 18 to 82 years (see Table 1). Scoring of the MEQ revealed that 33 participants were morning types, 24 were evening types, and 88 were neither type. There was no significant association between MEQ score and score on the ESS $\left(\mathrm{F}_{1,141}=2.71, P=0.1\right)$ or on the PSQI $\left(\mathrm{F}_{1,142}=0.04, P=0.8\right)$.

\section{Sleep timing}

MEQ score had a significant effect on weekday bedtime $\left(\mathrm{F}_{1,142}=86.24, P<0.0001\right)$ and wake time $\left(\mathrm{F}_{1,142}=51.46\right.$,
Table I Demographic and study information from all participants. Average ( \pm standard deviation) questionnaire responses from the 145 adult participants in the study are presented

\begin{tabular}{ll}
\hline All subjects & \\
\hline $\mathrm{n}$ & $\mathrm{I} 45$ \\
Age & $36.03 \pm \mathrm{I} 2.4$ \\
Sex & $9 \mathrm{I} \mathrm{f}, 54 \mathrm{~m}$ \\
MEQ types & $33 \mathrm{M}, 88 \mathrm{~N}, 24 \mathrm{E}$ \\
MEQ score & $50.86 \pm \mathrm{I} 0.6$ \\
PSQI score & $3.52 \pm \mathrm{I} .79$ \\
ESS score & $6.72 \pm 3.43$ \\
Weekday bed time & $23: 24 \pm \mathrm{I}: 29$ \\
Weekday wake time & $6: 56 \pm \mathrm{I}: 30$ \\
Weekend bed time & $24: 02 \pm \mathrm{I}: 30$ \\
Weekend wake time & $8: 25 \pm \mathrm{I}: 48$ \\
Weekend bed time delay & $0: 39 \pm 0: 48$ \\
Weekend wake time delay & $\mathrm{l}: 29 \pm \mathrm{I}: 18$ \\
Weekday sleep duration $(\mathrm{h})$ & $7.55 \pm \mathrm{I} .22$ \\
Weekend sleep duration $(\mathrm{h})$ & $8.38 \pm \mathrm{I} .36$ \\
Weekend sleep extension $(\mathrm{h})$ & $0.83 \pm \mathrm{I} .4$ \\
Perceived sleep need $(\mathrm{h})$ & $7.97 \pm \mathrm{I} .15$ \\
Weekday sleep deficit $(\mathrm{h})$ & $-0.42 \pm \mathrm{I} .4$ \\
Weekend sleep surplus $(\mathrm{h})$ & $+0.42 \pm \mathrm{I} .49$ \\
\hline
\end{tabular}

Abbreviations: MEQ, Morningness-Eveningness Questionnaire; ESS, Epworth Sleepiness score; PSQI, Pittsburgh Sleep Quality Index; M, morning; E, evening; $h$, hour; $\mathrm{N}$, neither; $f$, female; $m$, male.

$P<0.0001)$ as well as weekend bedtime $\left(\mathrm{F}_{1,142}=73.81\right.$, $P<0.0001)$ and wake time $\left(\mathrm{F}_{1,142}=119.21, P<0.0001\right)$. MEQ score also had a significant effect on the difference in wake time between weekdays and weekends $\left(\mathrm{F}_{1,142}=11.2, P<0.001\right.$; see Figure 1), but no significant effect on the difference in bedtime between weekdays and weekends $\left(\mathrm{F}_{1,142}=0.45, P=0.5\right)$.

\section{Sleep duration}

MEQ score had a significant effect on weekend sleep duration $\left(\mathrm{F}_{1,142}=6.82, P<0.01\right.$; see Figure 2), but not on weekday sleep duration $\left(\mathrm{F}_{1,142}=0.88, P=0.4\right)$. The change in sleep duration between weekdays and weekends was significantly influenced by MEQ score $\left(\mathrm{F}_{1,142}=12.01, P<0.001\right.$; see Figure 3$)$.

\section{Sleep need}

Prior to adjusting for age, we found a trend for an association between MEQ and self-reported sleep need $\left(\mathrm{F}_{1,142}=3.82\right.$, $P=0.053)$. However, with age included in the statistical model, MEQ score did not have a significant influence on reported sleep need $\left(\mathrm{F}_{1,141}=2.25, P=0.14\right)$. When we compared the difference between reported sleep need and weekday sleep duration, MEQ score had a significant influence $\left(\mathrm{F}_{1,141}=4.36, P<0.04\right)$, but it did not have a significant influence on the difference between sleep need and duration on the weekend $\left(\mathrm{F}_{1,141}=1.45, P=0.23\right)$. 


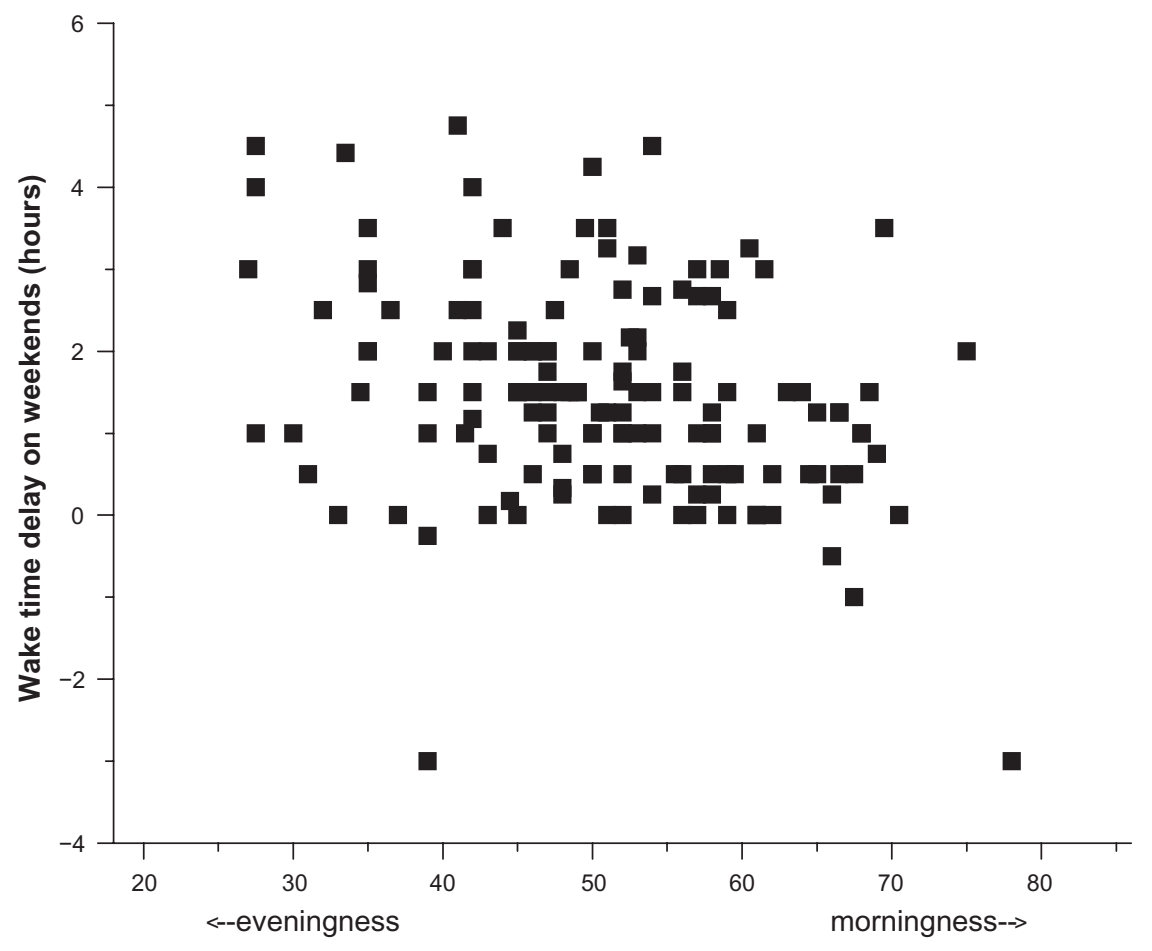

Morningness-Eveningness score

Figure I Relationship between MEQ score and delay of waketime on weekends. The delay of waketime (in hours) between weekdays and weekends for each of the 145 participants is plotted with respect to their MEQ score. MEQ scores can range from 18 to 86 , with higher numbers indicating greater morningness. Positive wake ime delays indicate later weekend than weekday waketimes, while negative delays indicate earlier weekend than weekday waketimes.

Abbreviation: MEQ, Morningness-Eveningness Questionnaire.

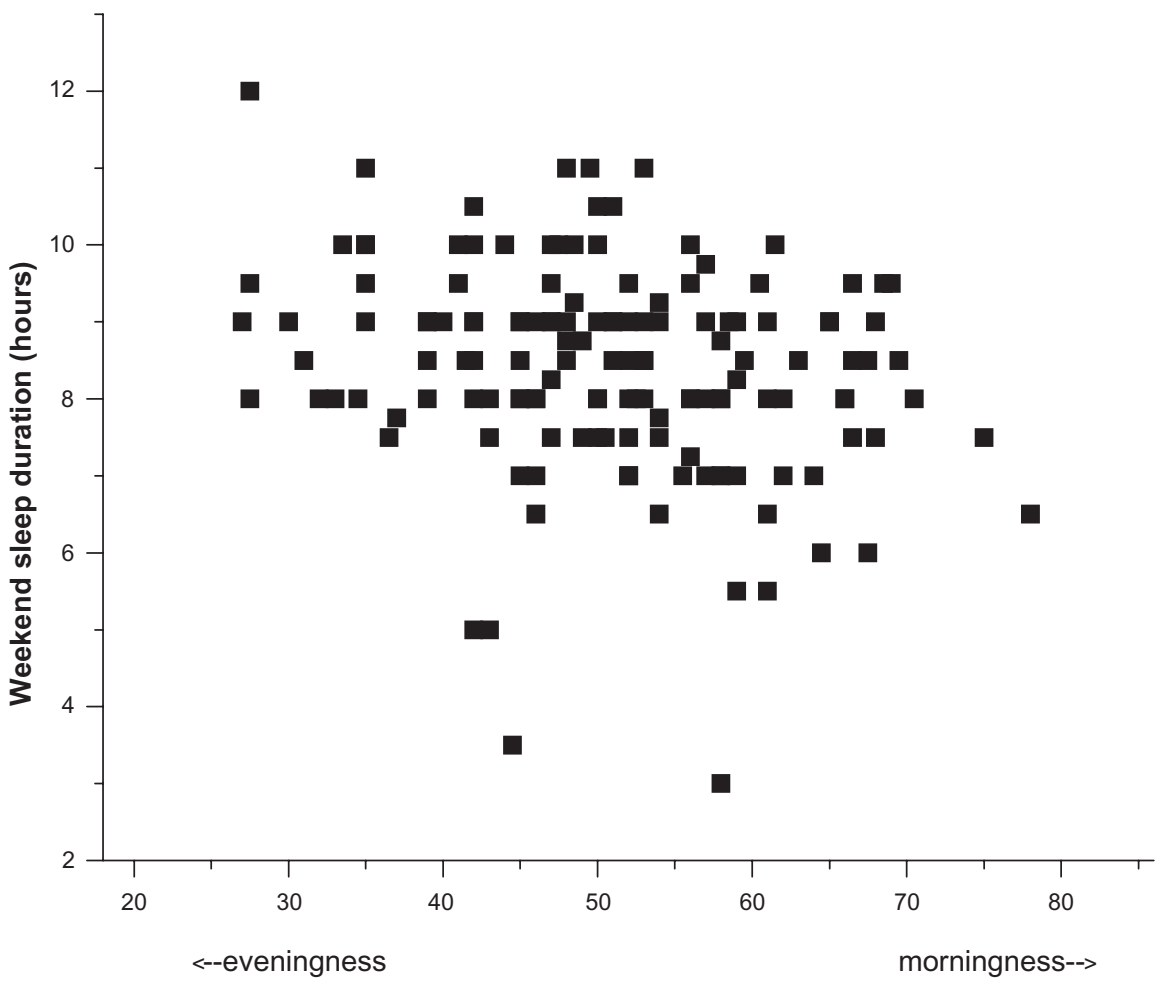

Morningness-Eveningness score

Figure 2 Relationship between MEQ score and weekend sleep duration. The weekend sleep duration (in hours) calculated from self-reported weekend bedtimes and waketimes for each of the 145 participants is plotted with respect to their MEQ score. MEQ scores can range from 18 to 86 , with higher numbers indicating greater morningness. Abbreviation: MEQ, Morningness-Eveningness Questionnaire. 


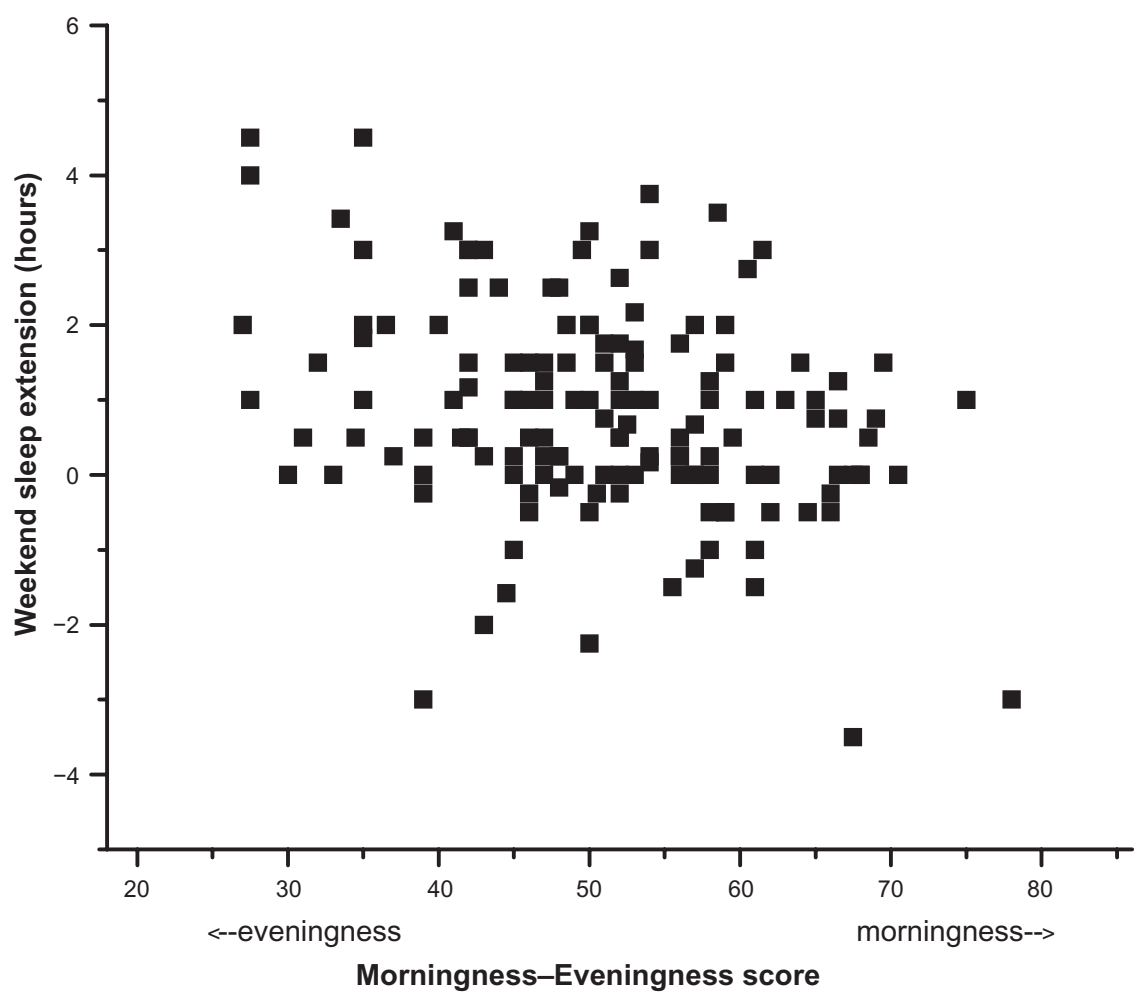

Figure 3 Relationship between MEQ score and weekend sleep extension. The extension of sleep (in hours) between weekdays and weekends calculated from self- reported weekday and weekend bed and wake for each of the 145 participants is plotted with respect to their MEQ score. MEQ scores can range from 18 to 86 , with higher numbers indicating greater morningness. Positive weekend sleep extensions indicate longer weekend than weekday sleep, while negative extensions indicate shorter weekend than weekday sleep. Abbreviation: MEQ, Morningness-Eveningness Questionnaire.

\section{Comparison of morning and evening types}

Our finding that MEQ score was associated with age (see Figure 4) also resulted in the subset of morning and evening types in our sample being significantly different in age (41.85 \pm 9.89 versus $31.54 \pm 12.68$ years, respectively, $P=0.001)$. We therefore conducted our comparisons of morning and evening types using a statistical model that included age as a covariate (see Table 2). On both weekdays and weekends, evening types had significantly later bed and wake times than morning types, even after controlling for age (see Table 2). While both groups delayed their bedtimes and wake times on weekends compared with the weekdays, the bedtime delay was similar between morning and evening types, while the wake time delay was slightly longer in the evening types than in the morning types (see Table 2). This delayed wake time on weekends resulted in the evening types having a significantly longer sleep duration on weekends than morning types (see Table 2), and a significantly greater difference between weekday and weekend sleep duration than morning types (see Table 2).

In order to compare the morning and evening types in our sample directly despite their significantly different ages, we use our statistical model solutions to age-adjust the observed sleep times and durations of the two groups. We adjusted the observed times in both morning and evening groups to age 35 years, which is the average age of the neither type subjects in our sample (see Table 2).

\section{Discussion}

In this study, we examined self-reported sleep timing, duration, and need in a group of adults. We were interested in whether chronotype influenced self-reported sleep need, and whether chronotype influenced the variability in sleep timing between weekdays and weekends. As has been shown previously, ${ }^{26,27,34,35}$ we found a significant association between age and chronotype in our sample, and the subset of morning types were significantly older than the evening types. When we controlled for age in our statistical model, we found that selfreported sleep need was not associated with MEQ and there were no significant differences in self-reported sleep need in the subset of morning and evening types in our sample.

One previous study by Taillard et al ${ }^{16}$ suggested that evening types may have an intrinsically greater sleep need than morning types. They reported that evening types had a 20-minute greater sleep need than morning or neither 


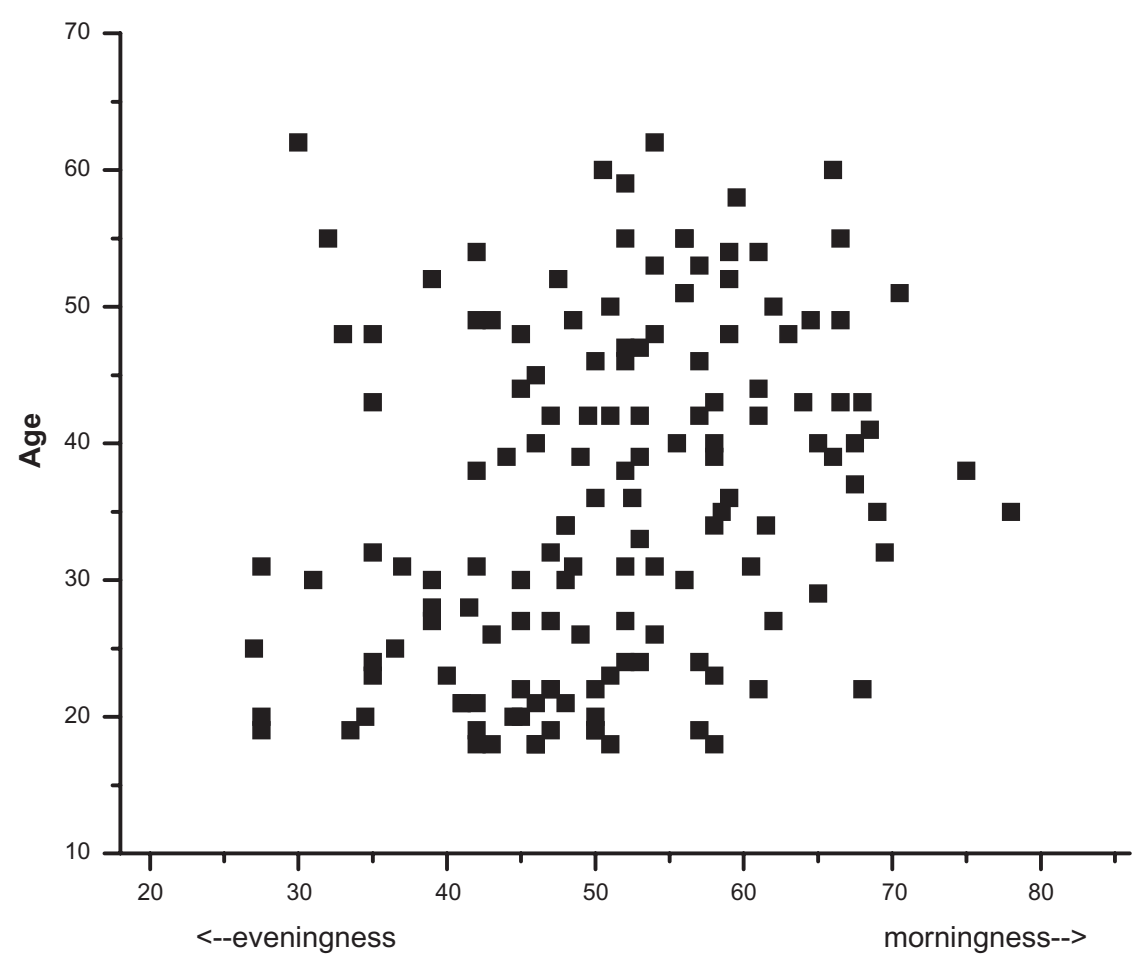

Morningness-Eveningness score

Figure 4 Relationship between MEQ score and age. The age (in years) for each of the 145 participants is plotted with respect to their MEQ score. MEQ scores can range from 18 to 86 , with higher numbers indicating greater morningness. There was a significant association between age and MEQ score when evaluated with a mixed model (see text) and there was a significant correlation (Pearson correlation coefficient $r=0.33, P<0.000 \mathrm{l}$ ).

Abbreviation: MEQ, Morningness-Eveningness Questionnaire.

types, and this difference was statistically significant. While we did not find a significant difference in reported sleep need, the age-adjusted sleep need in our evening types was 17.5 minutes longer than that of the morning types, very similar to the difference reported by Taillard et al. ${ }^{16}$
As expected, we found a significant association between MEQ and sleep-wake timing, both on the weekdays and on the weekends. Weekday sleep duration was not significantly influenced by MEQ. However, MEQ did have a significant impact on the weekday deficit between reported sleep

Table 2 Age-adjusted difference between subset of morning and evening types. Due to the significant difference in age between the morning and evening types in our sample, we included age in our statistical model when determining whether there were differences between the two chronotypes. The difference between evening and morning types (mean \pm standard error) and the associated $P$ value are presented. We calculated the mean value for each group by adjusting both groups to age 35 years, which was the average age of the neither type group of participants

\begin{tabular}{lllll}
\hline & M versus E difference & P value & $\begin{array}{l}\text { M mean } \\
\text { (age-adjusted) }\end{array}$ & $\begin{array}{l}\text { E mean } \\
\text { (age-adjusted) }\end{array}$ \\
\hline Weekday bed time & $2: 32 \pm 0: 22$ & 0.0001 & $22: 33$ & $1: 05$ \\
Weekday wake time & $2: 24 \pm 0: 23$ & 0.0001 & $6: 17$ & $8: 40$ \\
Weekend bed time & $2: 22 \pm 0: 21$ & 0.0001 & $23: 09$ & $1: 32$ \\
Weekend wake time & $3: 14 \pm 0: 23$ & 0.0001 & $7: 18$ & $10: 31$ \\
Weekend bed time delay & $-0: 10 \pm 0: 12$ & 0.4 & $0: 36$ & $0: 26$ \\
Weekend wake time delay & $0: 50 \pm 0: 26$ & 0.061 & $1: 01$ & $1: 51$ \\
Weekday sleep duration (h) & $-0.14 \pm 0.36$ & 0.7 & 7.73 & 7.58 \\
Weekend sleep duration (h) & $0.86 \pm 0.34$ & 0.015 & 8.13 & 8.99 \\
Weekend sleep extension (h) & $1.0 \pm 0.45$ & 0.031 & 0.41 & 1.41 \\
Perceived sleep need (h) & $0.29 \pm 0.26$ & 0.3 & 7.85 & 8.14 \\
PSQI score & $-0.04 \pm 0.51$ & 0.4 & 3.72 & 3.68 \\
ESS score & $-1.16 \pm 0.92$ & 0.2 & 7.74 & 6.58 \\
\hline
\end{tabular}

Abbreviations: ESS, Epworth Sleepiness score; PSQI, Pittsburgh Sleep Quality Index; M, morning; E, evening; h, hour. 
need and sleep duration, with greater deficits associated with eveningness, a finding similar to that reported previously in French drivers ${ }^{9}$ and Japanese workers. ${ }^{16,36}$ On the weekends, greater eveningness on the MEQ was associated with a significant delay in wake times (but not bed times), and was also associated with longer sleep durations. There was also a related influence of MEQ on the difference in sleep duration between weekdays and weekends, with significantly greater sleep extension on weekends associated with eveningness. We found similar relationships when we examined only that subset of the participants whose MEQ score indicated they were morning or evening type. Our findings suggest that despite the very small differences in weekday sleep duration and self- reported sleep need among different chronotypes, individuals who are more evening type appear to accumulate a small but significant sleep debt each night during the week. In fact, even though over the course of a week (including the weekend sleep extension) evening types reported sleeping about an hour longer than morning types, the difference between perceived sleep need and cumulative sleep duration resulted in a weekly sleep deficit of slightly more than an hour in evening types, whereas morning types achieved a balance between their perceived sleep need and reported sleep duration over the course of the week.

Laboratory studies have indicated that evening types are subjectively sleepier at wake time than morning types, and this may be related to differences in the biological time at which the two types sleep and wake. ${ }^{28,37}$ In fact, despite the later clock time at which they go to bed and awaken, many evening types are actually going to bed and getting up at an earlier biological time than morning types. Having to awaken at this earlier biological time to accommodate social demands may lead evening types to perceive their sleep duration as more inadequate than it might actually be. On weekends when they are less constrained by morning social demands, evening types may therefore not only extend their sleep until a more favorable biological time of awakening, but at the same time extend their sleep to make up the deficit accumulated during the work week. Whether this is the case in the participants in this study is unknown. However, the overall reported sleep quality on the PSQI of both morning and evening types was within the good sleeper range, indicating that both groups felt the quality of the sleep they got (irrespective of its duration) was adequate.

Together, our findings suggest that, on average, morning and evening types need similar amounts of sleep, and that morning types are able to match their sleep duration and sleep need closely across the week. Our findings dispute the idea that evening types need more sleep than morning types, but instead suggest that evening types accumulate a modest deficit between their perceived sleep need and their actual sleep duration across the working week, and then perhaps as a consequence extend their sleep significantly later on weekends. Our findings also reinforce the importance of accounting for age in any comparison of morning and evening types or any examination of selfreported sleep need.

\section{Limitations}

Our conclusions are limited by the nature of this questionnaire study, which relied on self- reports of sleep timing, which may have been inaccurate. In addition, because most visitors to the Museum were likely on a "day off" during their visit, their estimates of sleep timing and/or need may have been influenced by that fact. Our analysis relied on self-reports of sleep need, which have been shown in many prior studies to be inaccurate, although there are no reports suggesting that the degree of inaccuracy depends on chronotype or other sleep timing variables. We did not collect information about social factors or demands (such as childcare, work schedules, bed partners, sleeping environment) that may impact the timing and duration of sleep, and future studies of this nature should explore whether such factors differentially impact morning and evening chronotypes.

\section{Acknowledgments}

We wish to thank the Living Laboratory at the Museum of Science, Boston for allowing us to conduct the study; $\mathrm{T}$ Kardatzke and M Biarnes of the Museum of Science Boston, for providing training and assistance in implementing the study at the Museum; visitors to the Museum of Science Boston who took part in the study; Division of Sleep Medicine staff members, D Klements, R Pullman, M Surprise, and E Silva, for assistance conducting the study; staff members and volunteers in the Human Body Exhibit at the Museum of Science Boston; Dr W Wang for statistical advice; JM Ronda and CF Dennison for technical support; and Dr CA Czeisler for overall support. This research was supported in part by NIH grants HL080978 and AG09975; JFD is also supported by NIH grants HL077453 and AG06072.

\section{Disclosure}

The authors report no conflict of interest in this work. 


\section{References}

1. Horne J. Is there a sleep debt? Sleep. 2004;27:1047-1049.

2. Van Dongen HPA, Maislin G, Mullington JM, Dinges DF. The cumulative cost of additional wakefulness: Dose-response effects on neurobehavioral functions and sleep physiology from chronic sleep restriction and total sleep deprivation. Sleep. 2003;26:117-126.

3. Wingard DL, Berkman LF. Mortality risk associated with sleeping patterns among adults. Sleep. 1983;6:102-107.

4. Kripke DF, Garfinkel L, Wingard DL, Klauber MR, Marler MR. Mortality associated with sleep duration and insomnia. Arch Gen Psychiatry. 2002;59:131-136.

5. Spiegel K, Leproult R, Van Cauter E. Impact of sleep debt on metabolic and endocrine function. Lancet. 1999;354:1435-1439.

6. Meier-Ewert HK, Ridker PM, Rifai N, et al. Effect of sleep loss on $\mathrm{C}$-reactive protein, an inflammatory marker of cardiovascular risk. J Am Coll Cardiol. 2004;43:678-683.

7. Haack M, Sanchez E, Mullington JM. Elevated inflammatory markers in response to prolonged sleep restriction are associated with increased pain experience in healthy volunteers. Sleep. 2007;30:1145-1152.

8. Van Dongen HPA, Maislin G, Dinges DF. Dealing with inter-individual differences in the temporal dynamics of fatigue and performance: Importance and techniques. Aviat Space Environ Med. 2004;75 Suppl 3: A147-A154.

9. Wright KP Jr, Hull JT, Hughes RJ, Ronda JM, Czeisler CA. Sleep and wakefulness out of phase with internal biological time impairs learning in humans. J Cogn Neurosci. 2006;18:508-521.

10. Roehrs T, Shore E, Papineau K, Rosenthal L, Roth T. A two-week sleep extension in sleepy normals. Sleep. 1996;19:576-582.

11. Wehr TA. In short photoperiods, human sleep is biphasic. J Sleep Res. 1992;2:103-107.

12. Klerman EB, Dijk DJ. Age-related reduction in the maximal capacity for sleep - implications for insomnia. Curr Biol. 2008;18:1118-1123.

13. National Sleep Foundation. Executive summary of the 2005 "Sleep in America" poll. 2005. Available from: http://www.sleepfoundation. org/article/sleep-america-polls/2005-adult-sleep-habits-and-styles. Accessed Jul 31, 2010.

14. Hale L. Who has time to sleep? J Public Health (Oxf). 2005;27: 205-211.

15. Monk TH, Buysse DJ, Rose LR, Hall JA, Kupfer DJ. The sleep of healthy people - A diary study. Chronobiol Int. 2000;17:49-60.

16. Taillard J, Philip P, Bioulac B. Morningness/eveningness and the need for sleep. J Sleep Res. 1999;8:291-295.

17. Horne JA, Östberg O. A self-assessment questionnaire to determine morningness-eveningness in human circadian rhythms. Int J Chronobiol. 1976;4:97-110.

18. Duffy JF, Rimmer DW, Czeisler CA. Association of intrinsic circadian period with morningness-eveningness, usual wake time, and circadian phase. Behav Neurosci. 2001;115:895-899.

19. Park YM, Matsumoto K, Seo YJ, Shinkoda H. Sleep in relation to age, sex, and chronotype in Japanese workers. Percept Mot Skills. 1998;87: 199-215.

20. Schneider AM, Randler C. Daytime sleepiness during transition into daylight saving time in adolescents: Are owls at higher risk? Sleep Med. 2009; 10:1047-1050.

Nature and Science of Sleep

\section{Publish your work in this journal}

Nature and Science of Sleep is an international, peer-reviewed, open access journal covering all aspects of sleep science and sleep medicine, including the neurophysiology and functions of sleep, the genetics of sleep, sleep and society, biological rhythms, dreaming, sleep disorders and therapy, and strategies to optimize healthy sleep. The journal welcomes
21. Hublin C, Kaprio J, Partinen M, Koskenvuo M. Insufficient sleep A population- based study in adults. Sleep. 2001;24:392-400.

22. Hildebrandt G. Outline of chronohygiene. Chronobiologia. 1976;3: 113-127.

23. Breithaupt H, Hildebrandt G, Döhre D, Josch R, Sieber U, Werner M. Tolerance to shift of sleep, as related to the individual's circadian phase position. Ergonomics. 1978;21:767-774.

24. Hilliker NAJ, Muehlbach MJ, Schweitzer PK, Walsh JK. Sleepiness/ alertness on a simulated night shift schedule and morningnesseveningness tendency. Sleep. 1992;15:430-433.

25. Mongrain V, Carrier J, Dumont M. Circadian and homeostatic sleep regulation in morningness-eveningness. J Sleep Res. 2006;15: $162-166$.

26. Ishihara K, Miyake S, Miyasita A, Miyata Y. Morningness-eveningness preference and sleep habits in Japanese office workers of different ages. Chronobiologia. 1991;18:9-16.

27. Carrier J, Monk TH, Buysse DJ, Kupfer DJ. Sleep and morningnesseveningness in the 'middle' years of life (20-59 y). J Sleep Res. 1997;6: 230-237.

28. Duffy JF, Dijk DJ, Hall EF, Czeisler CA. Relationship of endogenous circadian melatonin and temperature rhythms to self-reported preference for morning or evening activity in young and older people. J Investig Med. 1999;47:141-150.

29. Duffy JF, Czeisler CA. Age-related change in the relationship between circadian period, circadian phase, and diurnal preference in humans. Neurosci Lett. 2002;318:117-120.

30. Bliwise DL. Normal aging. In: Kryger MH, Roth T, Dement WC, editors. Principles and Practice of Sleep Medicine. 4th ed. Philadelphia, PA: Elsevier Saunders; 2005.

31. Buysse DJ, Reynolds CF III, Monk TH, Berman SR, Kupfer DJ. The Pittsburgh sleep quality index: A new instrument for psychiatric practice and research. Psychiatry Res. 1989;28:193-213.

32. Johns MW. A new method for measuring daytime sleepiness: The Epworth sleepiness scale. Sleep. 1991;14:540-545.

33. Roenneberg T, Wirz-Justice A, Merrow M. Life between clocks: Daily temporal patterns of human chronotypes. J Biol Rhythms. 2003;18: 80-90.

34. Costa G, Lievore F, Ferrari P, Gaffuri E. Usual meal times in relation to age, sex, work activity and morningness-eveningness. Chronobiologia. 1987;14:383-391.

35. Monk TH, Reynolds CF III, Buysse DJ, et al. Circadian characteristics of healthy 80 -year-olds and their relationship to objectively recorded sleep. J Gerontol. 1991;46:M171-M175.

36. Ishihara K, Miyake S, Miyasita A, Miyata Y. Comparisons of sleepwake habits of morning and evening types in Japanese worker sample. J Human Ergol. 1988;17:111-118.

37. Baehr EK, Revelle W, Eastman CI. Individual differences in the phase and amplitude of the human circadian temperature rhythm: With an emphasis on morningness-eveningness. J Sleep Res. 2000;9: $117-127$.

\section{Dovepress}

original research, clinical \& epidemiological studies, reviews \& evaluations, case reports and extended reports. The manuscript management system is completely online and includes a very quick and fair peerreview system, which is all easy to use. Visit http://www.dovepress.com/ testimonials.php to read real quotes from published authors. 